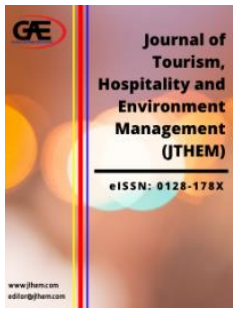

\author{
JOURNAL OF TOURISM, \\ HOSPITALITY AND \\ ENVIRONMENT MANAGEMENT \\ (JTHEM) \\ www.jthem.com
}

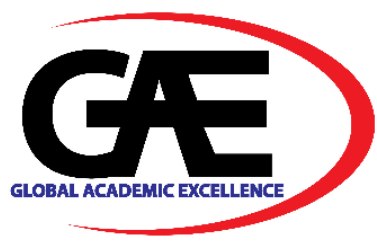

\title{
A SYSTEMATIC LITERATURE REVIEW OF SOCIAL NETWORK ANALYSIS IN TOURISM FLOWS
}

\author{
Tan Pei Yee ${ }^{*}$, Hairul Nizam Ismail ${ }^{2}$, Syed Muhammad Rafy Syed Jaafar ${ }^{3}$
}

$1 \quad$ Urban and Regional Planning, Faculty of Built Environment \& Surveying, Universiti Teknologi Malaysia, Malaysia Email: pytan4@graduate.utm.my

2 Urban and Regional Planning, Faculty of Built Environment \& Surveying, Universiti Teknologi Malaysia, Malaysia Email: b-hairul@utm.my

3 Urban and Regional Planning, Faculty of Built Environment \& Surveying, Universiti Teknologi Malaysia, Malaysia Email: s.rafy@utm.my

* Corresponding Author

\section{Article Info:}

\section{Article history:}

Received date: 01.10 .2021

Revised date: 01.11.2021

Accepted date: 15.11 .2021

Published date: 01.12.2021

\section{To cite this document:}

Tan, P. Y., Ismail, H. N., \& Jaafar, S. M. R. S. (2021). A Systematic Literature Review Of Social Network Analysis In Tourism Flows. Journal of Tourism Hospitality and Environment Management, 6 (26), 143-154.

DOI: $10.35631 /$ JTHEM.626012.

This work is licensed under CC BY 4.0

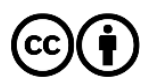

Abstract:

As the growing research interest and discussion on social network analysis associated with tourism flows, this paper reviewed 31 studies focused on tourism flows with social network analysis in the past ten years. To ensure the accuracy of the literature review, a systematic quantitative literature review with Preferred Reporting Items for Systematic Reviews and Meta-Analyses (PRISMA), together with descriptive and content analyses, was used to synthesise these past studies. With that, this review aims to (1) identify the overall research trends of social network analysis in tourism flows studies, (2) types and methods of data collection used, as well as (3) future research opportunities. The review findings present an interesting result with the past studies mostly focusing on examining tourist movement, tourism destination management, and tourist behavioural patterns. Furthermore, this review also provides significant findings on emerging data collection methods, like big data, in tourism research. To sum up, this paper offers an insight into social network analysis in tourism flows, primarily on the state of knowledge, methodological understanding, and future research gaps.

Keywords:

Social Network Analysis, Tourism Flows, Systematic Quantitative Literature Review, Descriptive Analysis, Content Analysis 


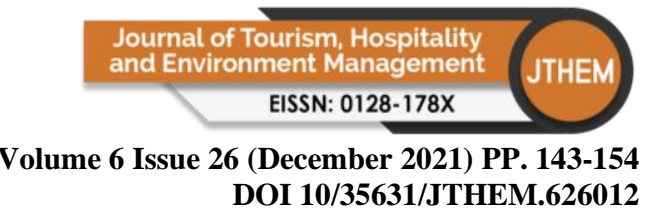

\section{Introduction}

\section{Social Network Analysis in Tourism}

Social network analysis is derived from the graph theory to explain the composition of a network. Links indicate relationships within a network, while nodes indicate individuals (Marin \& Wellman, 2011). This analysis relies upon either qualitative or quantitative approach to generate relevant network indicators and results, to accurately examine the attributes of the entire network and the function of individuals acting within the network structure (Shih, 2006). Apart from that, social network analysis in tourism is a recently emerging analytical method used to analyse the social phenomena based on the viewpoint of "network", classify destinations into a set of relationships, and describe destination features in the network structure (Tang \& Li, 2016).

The brief history of social network analysis in tourism studies can be traced to the early 2000s (Casanueva, Gallego, \& García-Sánchez, 2016). (Pavlovich, 2003) was the first researcher who implemented social network analysis into tourism research, objectively investigating the evolution and transformation of tourism destinations under tourism destination planning and management. Since then, many tourism studies began to utilise social network as the primary analysis method in empirically understanding the tourism phenomena (Z. Wang \& Liu, 2020). Apart from that, three types of tourism research directions allow studies to apply social network analysis, particularly with research that focus on (B. Liu, Huang, \& Fu, 2017; Racherla \& Hu, 2010; Ying \& Xiao, 2012):

1. Tourism research collaboration and knowledge creation,

2. Tourism supply, destination management and policy systems and

3. Tourist movements and behavioural patterns

\section{The Interaction Between Tourism Flows \& Social Network Analysis}

Tourism flows, also known as tourist flows, primarily indicate tourists' trajectories and related tourism activities in a specified geographical space (S. Zhong, Jie, \& LI, 2011). It reflects either the tourists' spatial-temporal behaviour at the destination, the movement pattern of tourists from the origin to the destination or within the destination (Caldeira \& Kastenholz, 2018; Zeng $\& \mathrm{He}, 2018$ ). Besides, tourism flows are not randomly formed in nature but patterned with the inertia of flows (Mansfeld, 1990), whilst fundamentally controlled by three basic elements, which are direction (static origin-destination configuration), the rate (the volume and frequency) and the link mode (dynamic connectivity) to visualise the spatial flows (Bowden, 2003). Previous studies have also found that social network analysis is best suited to plot and visualise tourism flows result (Peng, Zhang, Liu, Lu, \& Yang, 2016; Pu, Lu, Pu, Tao, \& Liu, 2019; Zeng, 2018).

\section{Aim and Objectives of the Review}

Although the reviews on social network analysis and tourism flows have been done before, they contain limitations related to scope and depth. First, (Casanueva et al., 2016) reviewed social network analysis in the overall context of tourism research and explicitly revealed the principal elements of social network analysis in tourism studies. Second, (Valeri \& Baggio, 2020) provided an overview of social network analysis in the form of the organisational implications of tourism management. Third, (Tan \& Ismail, 2020) used content analysis to review the evolution of tourism flows and factors influencing tourism flows pattern in the urban tourism context. Nevertheless, despite their limitations, these papers provide a comprehensive 


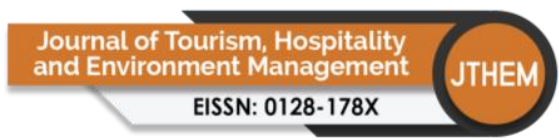

Volume 6 Issue 26 (December 2021) PP. 143-154

DOI 10/35631/JTHEM.626012

review of the current body of literature in both macro and micro contexts. Adding to these reviews, a vast number of empirical studies have applied social network analysis to analyse tourism flows structure. Yet, these past reviews could not capture and offer a detailed micro review, primarily linking tourism flows and social network analysis and demonstrating a relationship between both.

Furthermore, a thorough literature review is needed between both subjects despite the growing research interest and discussion on social network analysis and tourism flows. This paper, therefore, attempts to provide a comprehensive review with the following objectives:

a) To understand the overall research trends of social network analysis in tourism flows studies,

b) To identify the types and methods of data collection used in tourism flows associated with social network analysis, and

c) To identify areas and gaps for future research.

\section{Methodology}

This paper attempts to review the social network analysis in tourism flows using a "Systematic Quantitative Literature Review" method. A systematic quantitative literature review is suitable for identifying emerging research trends between two subjects and confining the boundary of knowledge into a specific scope (Pickering, Grignon, Steven, Guitart, \& Byrne, 2015). Given the review aims, the keywords such as "tourist flows" or "tourism flows" along with "social network analysis" were employed in the search for articles. The relevant research articles were obtained from primary index journal databases: Scopus and Web of Science (WoS). Additionally, the article search was only confined to the time frame of the recent ten years (from 2012-2021). The time frame was chosen due to the application of social network analysis in tourism flows, first seen in 2012 (Leung et al., 2012). A Preferred Reporting Items for Systematic Reviews and Meta-Analyses (PRISMA) analysis (Moher et al., 2014) was performed to run the article filtration process, as shown in Figure 1. The article searches in the primary index journal databases, produced 51 articles on record. A total of 12 articles were removed, as they were subject to duplication of articles, which left 39 articles available for a complete analysis. Six papers were eliminated in the screening process, as three articles were not focused on social network analysis, and the other three were not written in English. Following the literature selection criteria, two further articles were excluded in the eligibility process as the full text of those articles was not accessible. As a result, the total number of articles included in the final synthesis was 31 . The review synthesis was run, and the results were generated with Microsoft Excel. As seen in the summary table, descriptive and content analyses were used to elaborate on the review findings. 


\section{Figure 1: PRISMA Flowchart}

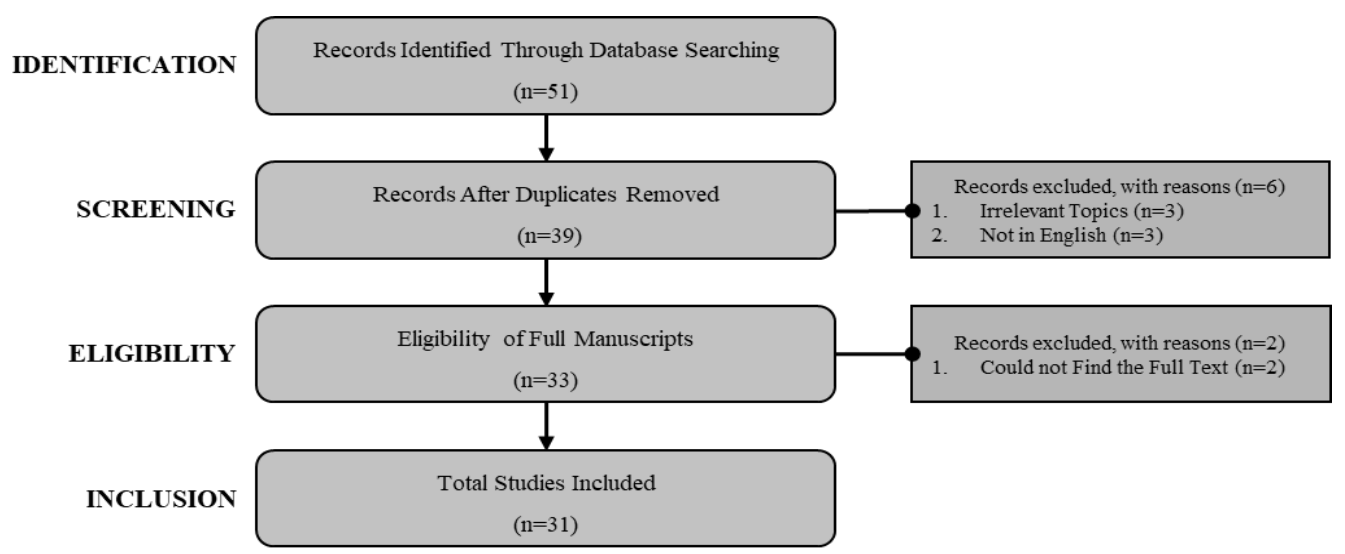

\section{Review Findings \& Discussion}

The review findings are organised into two sections according to each research objective. The first section applied descriptive analysis, while the second section used content analysis to elaborate the review findings further.

\section{Overview of Research Trends: Number of Publications Per Year}

One of the objectives of this review paper is to understand the overall emerging research trends on how social network analysis is associated with tourism flows studies. Figure 1 presents the number of published articles of social network analysis in tourism flows from 2012 to 2021. The line graph shows an overall positive upward trend. However, only three articles in the initial period from 2012 to 2015 were published when social network analysis was first introduced into tourism flows research. From 2016 until 2020, a continuously growing number of the published articles were recorded, with 25 articles found within the five-year range.

In 2020, the publication number peaked with nine articles published; this shows increasing interest from researchers on this emerging analysis method in tourism flows. It is worth noting that in the first quarter of 2021, the total number of published articles still indicates exponential growth. To sum it up, over the past ten years, the number of publications recorded was an average of 3.5 articles published per year. 


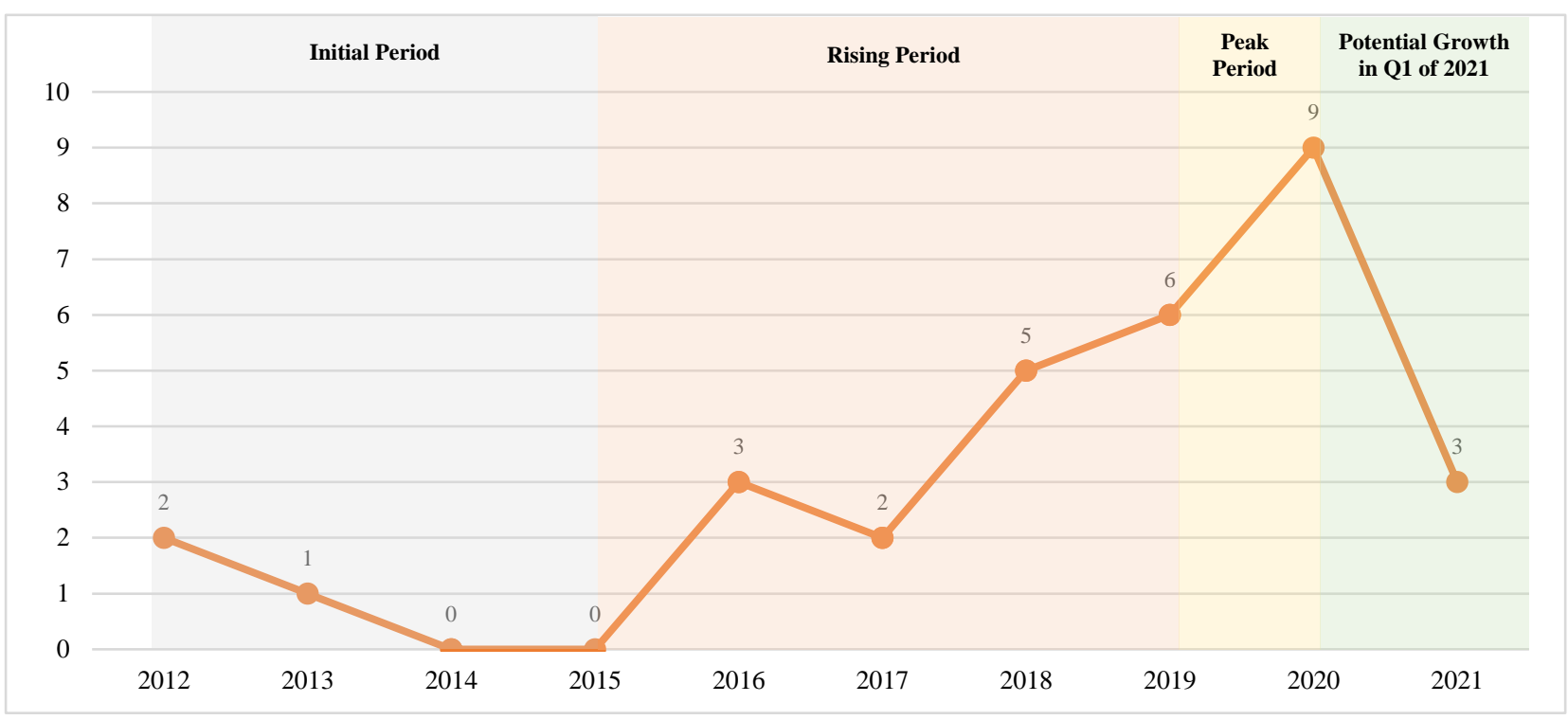

Figure 2: Distribution Of Publications Per Year From 2012 To 2021

\section{Overview of Research Trends: Journals and Proceeding Distribution}

Table 1 shows the distribution of journals and proceedings of the 31 selected articles in different publication platforms. The distribution between the journal articles and conference proceedings is 28 journals and three proceedings, accounting for approximately 90.38 per cent and 9.69 per cent, respectively. Meanwhile, the journal Sustainability (Switzerland) published the majority of the publications compared to other journals. This is followed by Tourism Management, Tourism Geographies, and the Journal of Travel Research. Remarkably, although Sustainability (Switzerland) comprised a higher proportion of the publication, most articles were published in tourism-related journals, with 12 different journal platforms listed. The second-ranked was in geography-related journals with four on record, which established the role of tourism flows in the setting of tourism and geography-related research fields.

\begin{tabular}{c|l|c|c}
\hline Discipline & \multicolumn{1}{|c|}{ Journals } & $\begin{array}{c}\text { No. of studies } \\
(\mathbf{n})\end{array}$ & $\begin{array}{c}\text { Per cent } \\
(\mathbf{\%})\end{array}$ \\
\hline $\mathrm{G}$ & Sustainability (Switzerland) & 6 & 19.35 \\
$\mathrm{~T}$ & Tourism Management & 2 & 6.45 \\
$\mathrm{~T}$ & Tourism Geographies & 2 & 6.45 \\
$\mathrm{~T}$ & Journal of Travel Research & 2 & 6.45 \\
$\mathrm{~T}$ & Annals of Tourism Research & 1 & 3.23 \\
$\mathrm{~T}$ & Journal of Destination Marketing \& \& & 1 & 3.23 \\
$\mathrm{~T}$ & Management & & \\
$\mathrm{T}$ & Tourism Management Perspectives & 1 & 3.23 \\
$\mathrm{~T}$ & Asia Pacific Journal of Tourism Research & 1 & 3.23 \\
$\mathrm{~T}$ & Journal of China Tourism Research & 1 & 3.23 \\
$\mathrm{~T}$ & International Journal of Tourism Research & 1 & 3.23 \\
$\mathrm{~T}$ & Tourism Planning \& Development & 1 & 3.23 \\
$\mathrm{G}$ & Journal of Vacation Marketing & 1 & 3.23 \\
$\mathrm{G}$ & Chinese Geographical Science & 1 & 3.23 \\
Copyright $\odot$ GLOBALACADEMIC EXCELENCE $(M)$ SDN BHD - All rights reserved & 1 & 3.23 \\
\end{tabular}




\begin{tabular}{|c|c|c|c|}
\hline \multicolumn{4}{|c|}{ DOI 10/35631/JTHEM.626012 } \\
\hline B & Research in World Economy & 1 & 3.23 \\
\hline B & Open Journal of Business and Management & 1 & 3.23 \\
\hline $\mathrm{E}$ & Journal of Mountain Science & 1 & 3.23 \\
\hline $\bar{C}$ & IEEE Access & 1 & 3.23 \\
\hline $\mathrm{T}$ & Information Technology \& Tourism & 1 & 3.23 \\
\hline M & Quality \& Quantity & 1 & 3.23 \\
\hline & Sub Total & 28 & 90.38 \\
\hline Discipline & Proceedings & $\begin{array}{l}\text { No. of studies } \\
\text { (n) }\end{array}$ & $\begin{array}{c}\text { Per cent } \\
(\%)\end{array}$ \\
\hline G & $\begin{array}{l}\text { IOP Conference Series: Earth and } \\
\text { Environmental Science } \\
\text { International Conference on Geo-Informatics } \\
\text { in Resource Management and Sustainable } \\
\text { Ecosystem }\end{array}$ & 1 & 3.23 \\
\hline $\mathrm{C}$ & Advances in Computer Science Research & 1 & 3.23 \\
\hline & Sub Total & 3 & 9.69 \\
\hline & TOTAL & 31 & 100 \\
\hline
\end{tabular}

Table 1: Distribution of Journals and Proceeding

\section{Overview of Research Trends: Research Topic Areas}

Table 2 summarises the coverage of research topic areas focusing on tourism flows using social network analysis. Based on the findings, 38.70 per cent of the research topics primarily focused on "tourist movement patterns". These studies examine the pattern of spatial tourism flows, contingent on tourism movement within destination and attractions or from the market source to destination and generated the results with the network analysis. Nine studies, or 29.03 per cent, focused on "tourism destination management". Compared with research focused on "tourist movement patterns", these "tourism destination management" focused studies specifically investigate destination-based tourism flows whereby the outcomes of studies are beneficial towards the planning and management of tourism destinations.

Studies on "behavioural patterns" consisted of 9.67 per cent of the overall research. These studies concentrated on destination-based tourism flows, mainly validating tourists' spatiotemporal behaviour across time and space. Meanwhile, studies that combined two subjects in one topic area were less studied, such as "tourism supply \& destination management", composed of only 6.45 per cent of the total research topics. It is the same case for "tourist movements \& destination management" and "behavioural patterns \& tourism supply", where both research topics represented only 3.23 per cent, respectively. Furthermore, only a limited number of studies concentrated on "tourism supply", "tourism research collaboration", and "tourism policy systems", with 3.23 per cent, respectively.

Table 2: Summary of Topic Areas

\begin{tabular}{l|c|c}
\hline \multicolumn{1}{c|}{ Topic Area } & No. of studies (n) & Per cent (\%) \\
\hline Tourist Movement Patterns & 12 & 38.70 \\
Tourism Destination Management & 9 & 29.03 \\
Behavioural Patterns & 3 & 9.67 \\
Tourism Supply \& Destination Management & 2 & 6.45 \\
Tourist Movements \& Destination Management & 1 & 3.23
\end{tabular}


Behavioural Patterns \& Tourism Supply

DOI 10/35631/JTHEM.626012

Tourism Supply

Tourism Research Collaboration

Tourism Policy Systems

TOTAL

1

1

1

31
3.23

3.23

3.23

3.23

Whilst, to interrelate with the publications per year, table 3 outlines the distribution of topic areas corresponding to the study's year of publication. As "tourist movement patterns" and "tourism destination management" were the most frequently studied topic areas, it came as no surprise that social network analysis began with both topics in tourism flows and continues to receive the most attention.

Table 3: Distribution of Topic Areas According to Publication Year

\begin{tabular}{l|c|c|c|c|c|c|c|c|c|c|c}
\hline \multirow{2}{*}{ Topic Area } & \multicolumn{7}{c|}{ Publications Year } & \multirow{2}{*}{ Total } \\
\cline { 2 - 8 } & $\mathbf{1 2}$ & $\mathbf{1 3}$ & $\mathbf{1 4}$ & $\mathbf{1 5}$ & $\mathbf{1 6}$ & $\mathbf{1 7}$ & $\mathbf{1 8}$ & $\mathbf{1 9}$ & $\mathbf{2 0}$ & $\mathbf{2 1}$ & \\
\hline Tourist Movement Patterns & 1 & & & & & & 2 & 3 & 5 & 1 & $\mathbf{1 2}$ \\
Tourism Destination Management & 1 & & & & 1 & 2 & & 1 & 2 & 2 & $\mathbf{9}$ \\
Behavioural Patterns & & & & & 1 & & 1 & 1 & & & $\mathbf{3}$ \\
Tourism Supply \& Destination & & & & & & & 1 & & 1 & & $\mathbf{2}$ \\
Management & & & & & & & & & & & $\mathbf{1}$ \\
Tourist Movements \& Destination & & & & & & & & & 1 & & \\
Management & & & & & & & & & & & $\mathbf{1}$ \\
Behavioural Patterns \& Tourism & & & & & & & 1 & & & & \\
Supply & & & & & & & & & & & $\mathbf{1}$ \\
Tourism Supply & & & & & 1 & & & & & & $\mathbf{1}$ \\
Tourism Research Collaboration & & 1 & & & & & & & & & $\mathbf{1}$ \\
Tourism Policy Systems & & & & & & & & 1 & & \\
\hline \multicolumn{1}{c|}{ TOTAL } & $\mathbf{2}$ & $\mathbf{1}$ & $\mathbf{0}$ & $\mathbf{0}$ & $\mathbf{3}$ & $\mathbf{2}$ & $\mathbf{5}$ & $\mathbf{6}$ & $\mathbf{9}$ & $\mathbf{3}$ & $\mathbf{3 1}$ \\
\hline
\end{tabular}

\section{Methods of Data Collection}

Table 4 shows a summary of the data collection methods based on the selected past studies. All the selected studies utilise empirical research; therefore, an explicit summarisation is allowed to further understand each method's characteristics. Meanwhile, the review findings reveal that the past studies collected more secondary data than primary data, regardless of which topic areas were studied. Furthermore, most studies collected secondary data due to the introduction of big data into tourism research in 2007 (Chareyron, Da-Rugna, \& Raimbault, 2014).

In the age of digital transformation, the advancement of internet technology and the high internet penetration rate enabled a vast number of data to be collected and processed in the form of user-created content (UGC) data, device data, and transactional data using multiple interconnected platforms, assuring simultaneous data quality (J. Li, Xu, Tang, Wang, \& $\mathrm{Li}$, 2018). User-created content (UGC) data is widely extracted from core online platforms, such as social media, where the data sources are mainly images and textual data. On the other hand, device data primarily corresponds to the GPS data, mainly extracted from intelligent devices such as mobile phones and Internet of Things (IoT) devices that connect wirelessly to a network and transmit data. Miscellaneous data and transactional data are generated, ranging from web searches, purchases, agreements, and other activities that happen through the network (Hashem et al., 2015). Reviews of organisational reports, such as UNWTO tourism statistical data, are 
also common methods to obtain data due to the high accessibility and availability rate coupled with nominal rates of data defects.

Conversely, primary data were frequently collected via questionnaire surveys, manual trip diaries, and integration between the questionnaire survey and the GPS logger. However, as time progressed, the relatively new studies in tourism flows applied with social network analysis tended to collect more secondary data than primary data. As research on tourism flows using social network analysis requires an extensive sample size (for primary data collection) or an extensive database (for secondary data collection) to assure a higher accuracy research outcome (Kádár \& Gede, 2021), it is understandable that past studies were much more reliant on secondary data. Nevertheless, both primary and secondary data worked well with social network analysis.

Table 4: Summary of Types \& Methods of Data Collected

\begin{tabular}{|c|c|c|c|}
\hline Author(s) & Primary & Secondary & Method of Data Collection \\
\hline \multicolumn{4}{|l|}{ Theme 1: Tourist Movements } \\
\hline (Wu, Wang, \& Liu, 2021) & & I & Transactional data \\
\hline (Mou et al., 2020) & & I & Travel notes \\
\hline (C. Y. Wang \& Kim, 2020) & & 1 & Travel notes \\
\hline (L. Zhong, Sun, Law, \& Yang, & & / & Device data \\
\hline 2020) & & & \\
\hline (A. Li et al., 2020) & & / & Device data \\
\hline (Shao, Huang, Wang, Li, \& Luo, & & / & UNWTO Statistical Data \\
\hline (Pu et al., 2019) & & / & Device data \\
\hline (Sugimoto, Ota, \& Suzuki, 2019) & I & & Questionnaire survey + GPS \\
\hline (Gao, Ye, Zhong, Wu, \& Liu, 2019) & & I & Transactional data \\
\hline (Zeng, 2018) & I & & Travel notes \\
\hline (Jin, Cheng, \& Xu, 2018) & & I & $\begin{array}{l}\text { User Generated Content } \\
\text { (UGC) data }\end{array}$ \\
\hline (Leung et al., 2012) & & I & $\begin{array}{l}\text { User Generated Content } \\
\text { (UGC) data }\end{array}$ \\
\hline
\end{tabular}

\section{Theme 2: Tourism Destination Management}

(Paulino, Lozano, \& Prats, 2021)

(Kádár \& Gede, 2021)

(Acampa, Grasso, Marino, \& Parisi, 2020)

(Seok, Barnett, \& Nam, 2020)

(Paulino, Prats, \& Whalley, 2019)

(B. Liu et al., 2017)

(Zhao, 2017)

(Peng et al., 2016)

(F. Liu et al., 2012)

Theme 3: Behavioural Patterns

(Du, Li, Pan, \& Zhang, 2019)

|

Geotagged pictures

User Generated Content

(UGC) data

Collection of reactions from

social media

UNWTO Statistical Data

Questionnaire survey

Questionnaire survey

Questionnaire survey

Questionnaire survey

Questionnaire survey

Transactional data 
Theme 4: Tourism Supply \& Destination Management

(Bianchi, Cappelletti, Mafrolla, Sica, \& Sisto, 2020)

(Fang \& Cooperat, 2018)

Geotagged pictures

\section{Theme 5: Tourist Movements \& Destination Management}

\begin{tabular}{|c|c|c|}
\hline (Z. Wang \& Liu, 2020) & I & Transactional data \\
\hline \multicolumn{3}{|c|}{ Theme 6: Behavioural Patterns \& Tourism Supply } \\
\hline (Van der Zee \& Bertocchi, 2018) & I & $\begin{array}{l}\text { User Generated Content } \\
\text { (UGC) }\end{array}$ \\
\hline \multicolumn{3}{|l|}{ Theme 7: Tourism Supply } \\
\hline (D. Wang et al., 2016) & I & Transactional data \\
\hline \multicolumn{3}{|c|}{ Theme 8: Tourism Research Collaboration } \\
\hline (Feng, Li, \& Zhang, 2013) & l & Transactional data \\
\hline \multicolumn{3}{|l|}{ Theme 9: Tourism Policy Systems } \\
\hline $\begin{array}{l}\text { (Chung, Herzberger, Frank, \& Liu, } \\
\text { 2019) }\end{array}$ & I & UNWTO Statistical Data \\
\hline
\end{tabular}

\section{Conclusion}

The paper offers a comprehensive literature review on the implication of social network analysis in tourism flows. A detailed explanation of the past studies' coverage topic areas and data collection methods is provided by synthesising 31 published studies from 2012 to 2021 without bias and included all the relevant publications. To recapitulate, the annual increase in the number of publications, mainly from 2016 to 2020, indicates the growing interest among researchers in this scope of the study. The review's trajectory presents the unbalanced research topic areas among those studies. The studies focused predominantly on tourist movement and tourism destination management and less on the combined subjects in one area. Regarding the study topic, the fourth industrial revolution (IR4.0) and the advancement of technology resulted in lesser primary data collected by researchers when big data analysis was introduced into tourism research. With the findings from the review, recommendations for future research opportunities can be proposed. As sustainable tourism development is a previous topic of study in tourism research, (Du et al., 2019), (L. Zhong et al., 2020), and (C. Y. Wang \& Kim, 2020) have recommended that future studies develop a more detailed research outcome for tourism flows studies with social network analysis. Therefore, future research could explore and explain tourism flows during different peak seasons, corresponding to the times and places needed to develop sustainable tourism. Future research can also consider employing a larger sample scale with better data collection methods to avoid data defects.

Moreover, this review complied with all its research objectives, first by clarifying the state of knowledge. Then, providing a methodological understanding of the data collection methods used. Lastly, by identifying future research gaps for researchers who wish to understand and use social network analysis as a spatial analysis tool in tourism flows or other subjects in tourism research. The limitations of this review paper are, firstly, it excluded the bibliometric findings of the literature review. A bibliometric analysis allows discovery of the research efficacy of individual scholars and institutions, research information flow, frequently cited scholars, and works (Chantre-Astaiza, Fuentes-Moraleda, Muñoz-Mazón, \& Ramirez- 


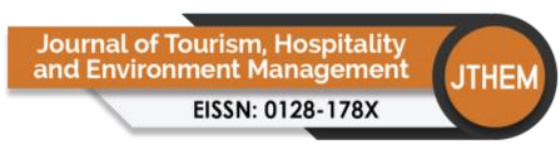

Volume 6 Issue 26 (December 2021) PP. 143-154 DOI 10/35631/JTHEM.626012

Gonzalez, 2019) to outline the significance of social network analysis in tourism flows studies. Secondly, this review does not synthesise the weaknesses and the inconveniences of social network analysis in the context of tourism flows. Despite the limitations, future researchers may also wish to review this topic further and extend the review findings with bibliometric analysis via science mapping tools or enhance the review by acknowledging the limitations of social network analysis.

\section{References}

Acampa, G., Grasso, M., Marino, G., \& Parisi, C. M. (2020). Tourist flow management: Social impact evaluation through social network analysis. Sustainability (Switzerland), 12(2).

Bianchi, P., Cappelletti, G. M., Mafrolla, E., Sica, E., \& Sisto, R. (2020). Accessible tourism in natural park areas: A social network analysis to discard barriers and provide information for people with disabilities. Sustainability (Switzerland), 12(23), 1-14.

Bowden, J. (2003). A cross-national analysis of international tourist flows in China. Tourism Geographies, 5(3), 257-279.

Caldeira, A. M., \& Kastenholz, E. (2018). Tourists' spatial behaviour in urban destinations: The effect of prior destination experience. Journal of Vacation Marketing.

Casanueva, C., Gallego, Á., \& García-Sánchez, M. R. (2016). Social network analysis in tourism. Current Issues in Tourism, 19(12), 1190-1209.

Chantre-Astaiza, A., Fuentes-Moraleda, L., Muñoz-Mazón, A., \& Ramirez-Gonzalez, G. (2019). Science mapping of tourist mobility 1980-2019. Technological advancements in the collection of the data for tourist traceability. Sustainability (Switzerland), 11(17), $1-32$.

Chareyron, G., Da-Rugna, J., \& Raimbault, T. (2014). Big data: A new challenge for tourism. 2014 IEEE International Conference on Big Data (Big Data), 5-7. Washington, DC, USA: IEEE.

Chung, M. G., Herzberger, A., Frank, K. A., \& Liu, J. (2019). International Tourism Dynamics in a Globalized World: A Social Network Analysis Approach. Journal of Travel Research, 59(3), 387-403.

Du, Y., Li, J., Pan, B., \& Zhang, Y. (2019). Lost in Thailand: A case study on the impact of a film on tourist behavior. Journal of Vacation Marketing, 26(3), 365-377.

Fang, W., \& Cooperat, C. S. (2018). Belt or net twork? The spatial struct ture a and sha aping mech anism of o the Great Wall cul tural be elt in B Beijing. Journal of Mountain Science, 15(2), 2027-2042.

Feng, N., Li, J., \& Zhang, G. (2013). A study of the structure of China's mainstream online tourism information network based on SNA. Communications in Computer and Information Science, 399 PART I, 541-552.

Gao, Y., Ye, C., Zhong, X., Wu, L., \& Liu, Y. (2019). Extracting spatial patterns of intercity tourist movements from online travel blogs. Sustainability (Switzerland), 11(13), 1-18.

Hashem, I. A. T., Yaqoob, I., Anuar, N. B., Mokhtar, S., Gani, A., \& Ullah Khan, S. (2015). The rise of "big data" on cloud computing: Review and open research issues. Information Systems, 47, 98-115.

Jin, C., Cheng, J., \& Xu, J. (2018). Using User-Generated Content to Explore the Temporal Heterogeneity in Tourist Mobility. Journal of Travel Research, 57(6), 779-791.

Kádár, B., \& Gede, M. (2021). Tourism flows in large-scale destination systems. Annals of Tourism Research, 87, 103113. 


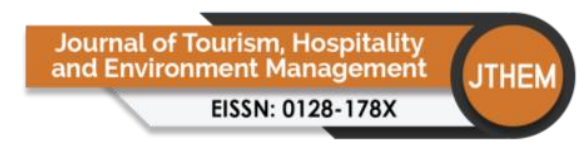

Volume 6 Issue 26 (December 2021) PP. 143-154

DOI 10/35631/JTHEM.626012

Leung, X. Y., Wang, F., Wu, B., Bai, B., Stahura, K. A., \& Xie, Z. (2012). A Social Network Analysis of Overseas Tourist Movement Patterns in Beijing: the Impact of the Olympic Games. International Journal of Tourism Research, 14(5), 469-484.

Li, A., Mou, N., Zhang, L., Yang, T., Liu, W., \& Liu, F. (2020). Tourism Flow between Major Cities during China's National Day Holiday: A Social Network Analysis Using Weibo Check-in Data. IEEE Access, 8, 225675-225691.

Li, J., Xu, L., Tang, L., Wang, S., \& Li, L. (2018). Big data in tourism research: A literature review. Tourism Management, 68, 301-323.

Li, Y., Xie, J., Gao, X., \& Law, A. (2018). A Method of selecting potential development regions based on GPS and social network models - from the perspective of tourist behavior. Asia Pacific Journal of Tourism Research, 26(2), 183-199.

Liu, B., Huang, S. (Sam), \& Fu, H. (2017). An application of network analysis on tourist attractions: The case of Xinjiang, China. Tourism Management, 58, 132-141.

Liu, F., Zhang, J., Zhang, J., Chen, D., Liu, Z., \& Lu, S. (2012). Roles and functions of tourism destinations in tourism region of South Anhui: A tourist flow network perspective. Chinese Geographical Science, 22(6), 755-764.

Mansfeld, Y. (1990). Spatial patterns of international tourist flows: Towards a theoretical framework. Progress in Human Geography, 14(3), 372-390.

Marin, A., \& Wellman, B. (2011). Social Network Analysis: An Introduction. In J. Scott \& P. J. Carrington (Eds.), The SAGE Handbook of Social Network Analysis (pp. 11-25). London: Sage Publications Ltd.

Moher, D., Liberati, A., Tetzlaff, J., Altman, D. G., Antes, G., Atkins, D., ... Tugwell, P. (2014). Preferred reporting items for systematic review and meta-analysis protocols (PRISMA-P) 2015: elaboration and explanation. Revista Espanola de Nutricion Humana y Dietetica.

Mou, N., Zheng, Y., Makkonen, T., Yang, T., Tang, J., \& Song, Y. (2020). Tourists' digital footprint: The spatial patterns of tourist flows in Qingdao, China. Tourism Management, 81(104151).

Paulino, I., Lozano, S., \& Prats, L. (2021). Identifying tourism destinations from tourists' travel patterns. Journal of Destination Marketing and Management, 19(October 2020), 100508.

Paulino, I., Prats, L., \& Whalley, P. A. (2019). Establishing Influence Areas of Attractions in Rural Destinations. Tourism Planning and Development, 17(6), 611-635.

Pavlovich, K. (2003). The evolution and transformation of a tourism destination network: the Waitomo Caves, New Zealand. Tourism Management, 24(2), 203-216.

Peng, H., Zhang, J., Liu, Z., Lu, L., \& Yang, L. (2016). Network analysis of tourist flows: a cross-provincial boundary perspective. Tourism Geographies, 18(5), 561-586.

Pickering, C., Grignon, J., Steven, R., Guitart, D., \& Byrne, J. (2015). Publishing not perishing: How research students transition from novice to knowledgeable using systematic quantitative literature reviews. Studies in Higher Education, 40(10), 1756-1769.

Pu, R., Lu, S., Pu, Y., Tao, Z., \& Liu, P. (2019). Study on Tourist Flow Network Structure in Jiangsu Province. IOP Conference Series: Earth and Environmental Science, 310(5), 1-6. IOP Publishing Ltd.

Racherla, P., \& Hu, C. (2010). A social network perspective of tourism research collaborations. Annals of Tourism Research, 37(4), 1012-1034.

Seok, H., Barnett, G. A., \& Nam, Y. (2020). A social network analysis of international tourism flow. Quality and Quantity, 55(2), 419-439. 


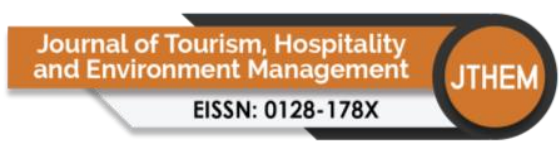

Volume 6 Issue 26 (December 2021) PP. 143-154

DOI 10/35631/JTHEM.626012

Shao, Y., Huang, S. (Sam), Wang, Y., Li, Z., \& Luo, M. (2020). Evolution of international tourist flows from 1995 to 2018: A network analysis perspective. Tourism Management Perspectives, 36(24), 100752.

Shih, H. Y. (2006). Network characteristics of drive tourism destinations: An application of network analysis in tourism. Tourism Management, 27(5), 1029-1039.

Sugimoto, K., Ota, K., \& Suzuki, S. (2019). Visitor mobility and spatial structure in a local urban tourism destination: GPS tracking and network analysis. Sustainability (Switzerland), 11(3).

Tan, P. Y., \& Ismail, H. N. (2020). A Review on Spatial Tourist Flows Pattern in Urban Tourism Development. International Graduate Conference on Engineering, Science and Humanities (IGCESH), 472-476. Johor Bahru: Universiti Teknologi Malaysia (UTM).

Tang, J., \& Li, J. (2016). Spatial network of urban tourist flow in Xi'an based on microblog big data. Journal of China Tourism Research, 12(1), 5-23.

Valeri, M., \& Baggio, R. (2020). Social network analysis: organizational implications in tourism management. International Journal of Organizational Analysis.

Van der Zee, E., \& Bertocchi, D. (2018). Finding patterns in urban tourist behaviour: a social network analysis approach based on TripAdvisor reviews. Information Technology and Tourism, 20(1-4), 153-180.

Wang, C. Y., \& Kim, H. H. (2020). Analysis on the characteristics of tourism flow of Chinese independent tourists in Vietnam. Research in World Economy, 11(2), 122-128.

Wang, D., Wang, L., Chen, T., Lu, L., Niu, Y., \& Alan, A. L. (2016). HSR mechanisms and effects on the spatial structure of regional tourism in China. Journal of Geographical Sciences, 26(12), 1725-1753.

Wang, Z., \& Liu, Y. (2020). Seasonal Characteristics of Tourism Flow Network Structure in Guangdong Residents from the Perspective of Social Network. Open Journal of Business and Management, 08(02), 683-695.

Wu, S., Wang, L., \& Liu, H. (2021). Study on tourism flow network patterns on may day holiday. Sustainability (Switzerland), 13(2), 1-23.

Ying, T., \& Xiao, H. (2012). Knowledge Linkage: A Social Network Analysis of Tourism Dissertation Subjects. Journal of Hospitality \& Tourism Research, 36(4), 450-477.

Zeng, B. (2018). Pattern of Chinese tourist flows in Japan: a Social Network Analysis perspective. Tourism Geographies, 20(5), 810-832.

Zeng, B., \& He, Y. (2018). Factors influencing Chinese tourist flow in Japan-a grounded theory approach. Asia Pacific Journal of Tourism Research, 24(1), 56-69.

Zhao, J. (2017). Study on Structure of Inbound Tourism Network of Key Tourist cities in Henan Province. 7th International Conference on Education, Management, Information and Mechanical Engineering (EMIM 2017) Study, 76, 673-680. Advances in Computer Science Research (ACSR).

Zhong, L., Sun, S., Law, R., \& Yang, L. (2020). Investigate tourist behavior through mobile signal: Tourist flow pattern exploration in tibet. Sustainability (Switzerland), 12(21), 113.

Zhong, S., Jie, Z., \& LI, X. (2011). A reformulated directional bias of tourist flow. Tourism Geographies, 13(1), 129-147. 